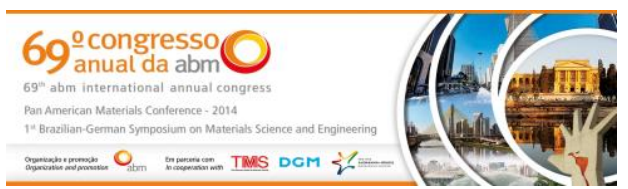

Tema: Produtos metálicos ferrosos

\title{
RELAÇÃO ENTRE QUANTIFICAÇÃO MICROESTRUTURAL E COMPORTAMENTO MECANICO DE AÇOS API/DNV PARA LINEPIPES*
}

\section{Resumo}

\author{
Rodrigo Galves De Lucca ${ }^{1}$ \\ Sergio Henrique dos Santos ${ }^{2}$ \\ Izabela Ferreira Girão ${ }^{3}$ \\ Benedito Carlos Cavalheiro 4 \\ Marcelo Re Salani ${ }^{5}$ \\ Ronaldo Cristiano da Silva ${ }^{6}$ \\ Marcelo Carlos Fritz ${ }^{7}$
}

As tendências do mercado são de utilizar tubos com maior resistência e tenacidade para a temperatura de projeto. Resultados obtidos em testes de laboratório para diferentes ordens de produção e graus, a partir de testes de tração de chapas e tubos, juntamente com a quantificação microestrutural, proporcionam uma oportunidade para melhor compreender e quantificar a influência de cada fase sobre o comportamento das propriedades mecânicas do material. A presença de maiores quantidades de ferrita acicular/ferrita poligonal, em vez de ferrita poligonal/perlita, geram um aumento das propriedades mecânicas durante a formação do tubo, bem como uma forma bem definida do comportamento de tensão-deformação, o que é benéfico em aplicações de strain based design.

Palavras-chave: Quantificação microestrutural; Comportamento mecânico; Linepipe; ARBL.

\section{CORRELATION BETWEEN MICROSTRUCTURE QUANTIFICATION AND MECHANICAL BEHAVIOR FOR API/DNV LINEPIPE STEELS}

\section{Abstract}

Market trends are of using pipes with higher strength and toughness for the desired operation temperature. Results obtained at laboratory tests for different pipe orders and grades, from tensile testing of plates and pipes, along with microstructure quantification, provide an opportunity to better understand and quantify the influence of each phase on the behavior of the material's mechanical properties. The presence of higher amounts of acicular ferrite/polygonal ferrite, instead of polygonal ferrite/perlite, yields in an increase of mechanical properties during pipe formation, as well as a defined round-house shape of the stress-strain behavior, which is beneficial to strain based applications.

Keywords: Microstructure quantification; Mechanical behavior; Linepipe; HSLA.

1 Eng. de Materiais, Eng. Desenv. de Produto, Tenaris, Pindamonhangaba, SP, Brasil; rglucca@tenaris.com.

2 Eng. Mecânico, Eng. Desenv. de Produto, Tenaris, Pindamonhangaba, SP, Brasil; shsantos@tenaris.com.

3 Eng. de Materiais, Eng. Metalurgia, Tenaris, Pindamonhangaba, SP, Brasil; igirao@tenaris.com.

4 Bacharel em Física, Especialista em Metalurgia, Tenaris, Pindamonhangaba, SP Brasil; bcavalheiro@tenaris.com.

5 Mestre, Eng. Mecânica ênfase em Materiais, Eng. Metalurgista, Gerente de Metalurgia e Laboratório, Tenaris, Pindamonhangaba, SP, Brasil; msalani@tenaris.com.

6 Mestre em Materiais e Metalurgia, Eng. Mecânico, Gerente de Desenvolvimento de Produto, Tenaris, Pindamonhangaba, SP, Brasil; rsilva@tenaris.com.

7 Eng. Mecânico, Diretor de Qualidade, Tenaris, Pindamonhangaba, SP, Brasil; mfritz@tenaris.com.

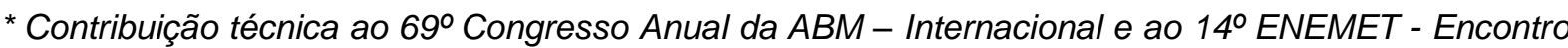
Nacional de Estudantes de Engenharia Metalúrgica, de Materiais e de Minas, 21 a 25 de julho de 2014, São Paulo, SP, Brasil.
} 


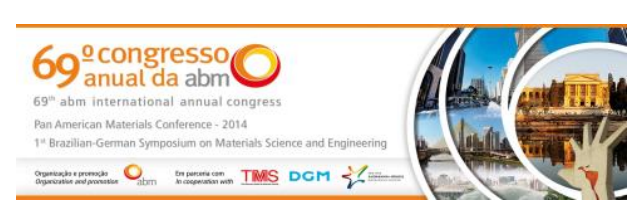

\section{INTRODUÇÃO}

A projeção do aumento do consumo mundial de derivados do óleo e gás, juntamente com a tendência de aumento dos preços dos barris de petróleo e do metro cúbico de gás, cria uma força motriz para a exploração de novas fontes destes produtos. De acordo com a revisão anual de estatística de energia mundial publicada pela British Petroleum [1], o crescimento da produção de petróleo e de gás natural entre 2011 e 2012 foi de $2,2 \%$ e de $1,9 \%$, respectivamente. A fim de escoar o crescente volume produzido, são necessárias as criações de novas linhas de escoamento, conhecidas como pipelines, tanto em regiões em terra, onshore, quanto em regiões marítimas, offshore.

O Brasil também será afetado pelo aumento do consumo e da produção de derivados do petróleo. A figura 1 mostra como a produção e o consumo de petróleo bruto tem crescido nos últimos 20 anos, sendo possível observar que a produção de petróleo tem um crescimento maior que o consumo do mesmo. Até 2035, o Brasil, de acordo com o estudo da British Petroleum [1], se tornará exportador de energia, apresentando um aumento de produção de $98 \%$ em relação a 2012 enquanto a demanda deverá aumentar $71 \%$. É previsto também um aumento na produção de óleo e de gás natural de $109 \%$ e $178 \%$, respectivamente. Desta maneira, o Brasil também irá necessitar criar novas maneiras para escoar todo o produto produzido.

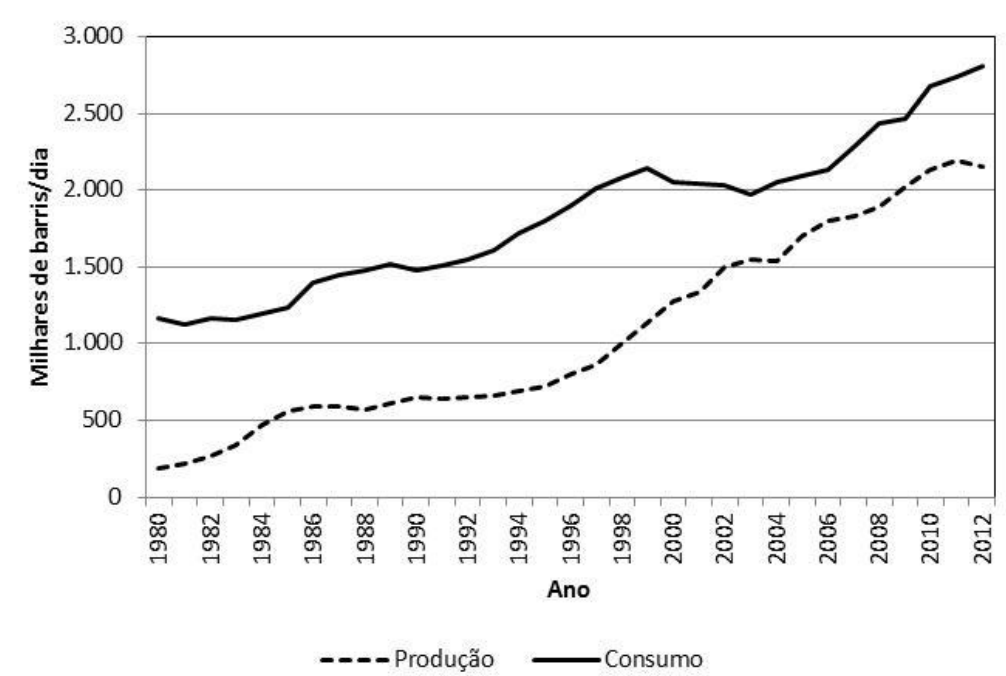

Figura 1. Histórico de produção e consumo de petróleo bruto no Brasil. Dados obtidos em estudo da British Petroleum [1]

Uma maneira encontrada pelas operadoras para a redução de custos envolvidos na instalação de novas linhas transportadoras é a utilização de tubos API/DNV de grande diâmetro com resistência cada vez maior, conforme descrito por Sanderson et al [2]. Desta maneira é possível minimizar custos alterando-se, por exemplo, o dimensional dos tubos para atender uma mesma vazão de produtos em seu interior. Às condições locais da região de instalação dos tubos das linhas transportadoras, como a presença de instabilidades geológicas, proximidade com regiões habitadas, alta lâmina d'agua e presença de hidróxido de enxofre no ambiente, tem aumentado conforme a exploração do petróleo e do gás avança para ambientes de mais difícil acesso. A necessidade de suportar ambientes mais severos faz com que haja necessidade de um maior controle de propriedades mecânicas e dimensionais dos tubos envolvidos. Desta maneira cada vez mais projetos de linhas transportadoras

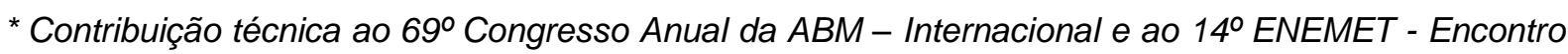
Nacional de Estudantes de Engenharia Metalúrgica, de Materiais e de Minas, 21 a 25 de julho de 2014, São Paulo, SP, Brasil.
} 


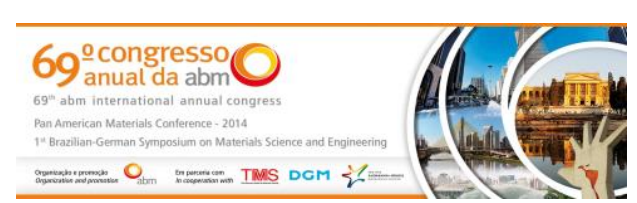

utilizam-se das propriedades mecânicas conhecidas, como a deformação dentro do limite elástico, durante a etapa de projeto, como exemplificado por Willian Mohr [3]. Sendo assim é necessário assegurar que tais propriedades sejam estabelecidas e previsíveis para garantir a integridade dos tubos, iniciando o controle desde a produção das chapas grossas até no processo de fabricação dos tubos.

O processo de fabricação de chapas comumente utilizado é a laminação controlada, seguida ou não do resfriamento acelerado. O processo de laminação controlada é dividido em duas partes: a laminação desbastadora e a laminação final. Durante a etapa de desbaste, a placa é reduzida a dimensões próximas às finais, utilizando-se de altas taxas de deformação a altas temperaturas. No processo de laminação final, a placa é deformada abaixo da temperatura de não recristalização da austenita. O interior dos grãos de austenita encruada servem então como sítios preferenciais, junto aos sítios localizados nos contornos de grão, para a nucleação da fase ferritica e bainitica. Desta maneira, a microestrutura final obtida é de grãos extremamente finos, o que contribui para o aumento da resistência mecânica do material, assim como sua soldabilidade. A utilização da etapa de resfriamento acelerado garante ainda o ajuste final de quantidade de fases ferríticas / bainíticas presentes na microestrutura. A figura 2, abaixo, exemplifica diferentes rotas de laminação para 0 material X100, conforme estudado por Nafisi et al [4].

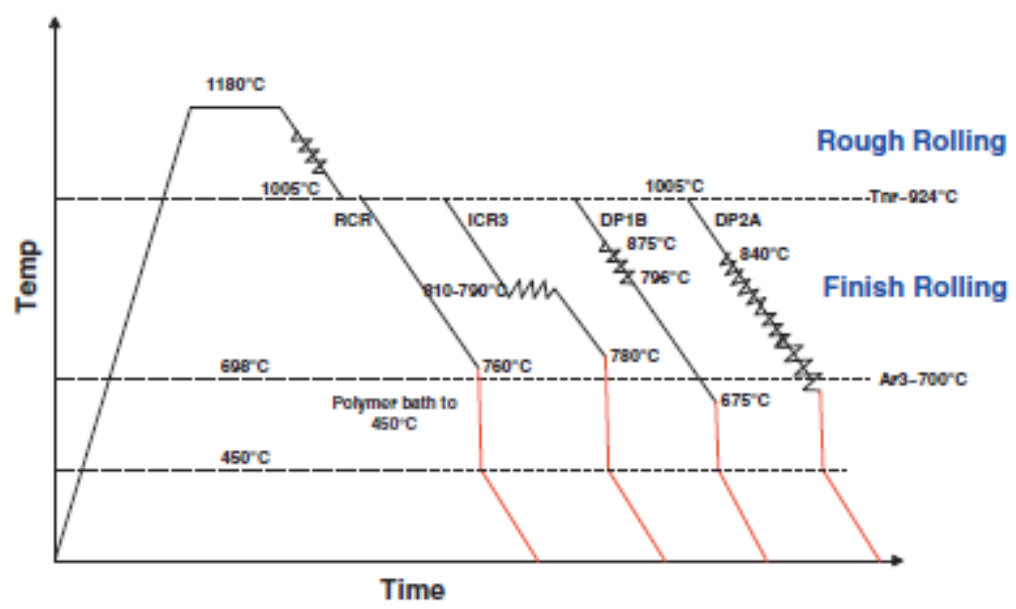

Figura 2. Diferentes rotas de laminação para o material X100 [4]

A etapa de produção dos tubos, a partir das chapas laminadas, também é de extrema importância nas propriedades finais do mesmo. É sabido que as propriedades mecânicas finais do tubo são dependentes de diversos fatores, como a composição química e a microestrutura da chapa e as deformações provenientes do processo de conformação. O processo de fabricação de tubos de grande diâmetro comumente aplicados para este produto é denominado de "UOE". Este processo consiste de etapas de deformação realizadas em 3 prensas e 1 expansor, sendo a primeira etapa a prensa de bordas, ou prensa " $C$ ", seguida da prensa " $U$ " e prensa "O". Após a prensagem, os tubos são soldados longitudinalmente pelo processo SAW. A última etapa é a expansão mecânica, que garante o dimensional e as propriedades mecânicas dos tubos. O diagrama representando a fabricação dos tubos pode ser observado na figura 3 .

\footnotetext{
* Contribuição técnica ao $69^{\circ}$ Congresso Anual da ABM - Internacional e ao 14ํㅡㄹ ENEMET - Encontro Nacional de Estudantes de Engenharia Metalúrgica, de Materiais e de Minas, 21 a 25 de julho de 2014, São Paulo, SP, Brasil.
} 

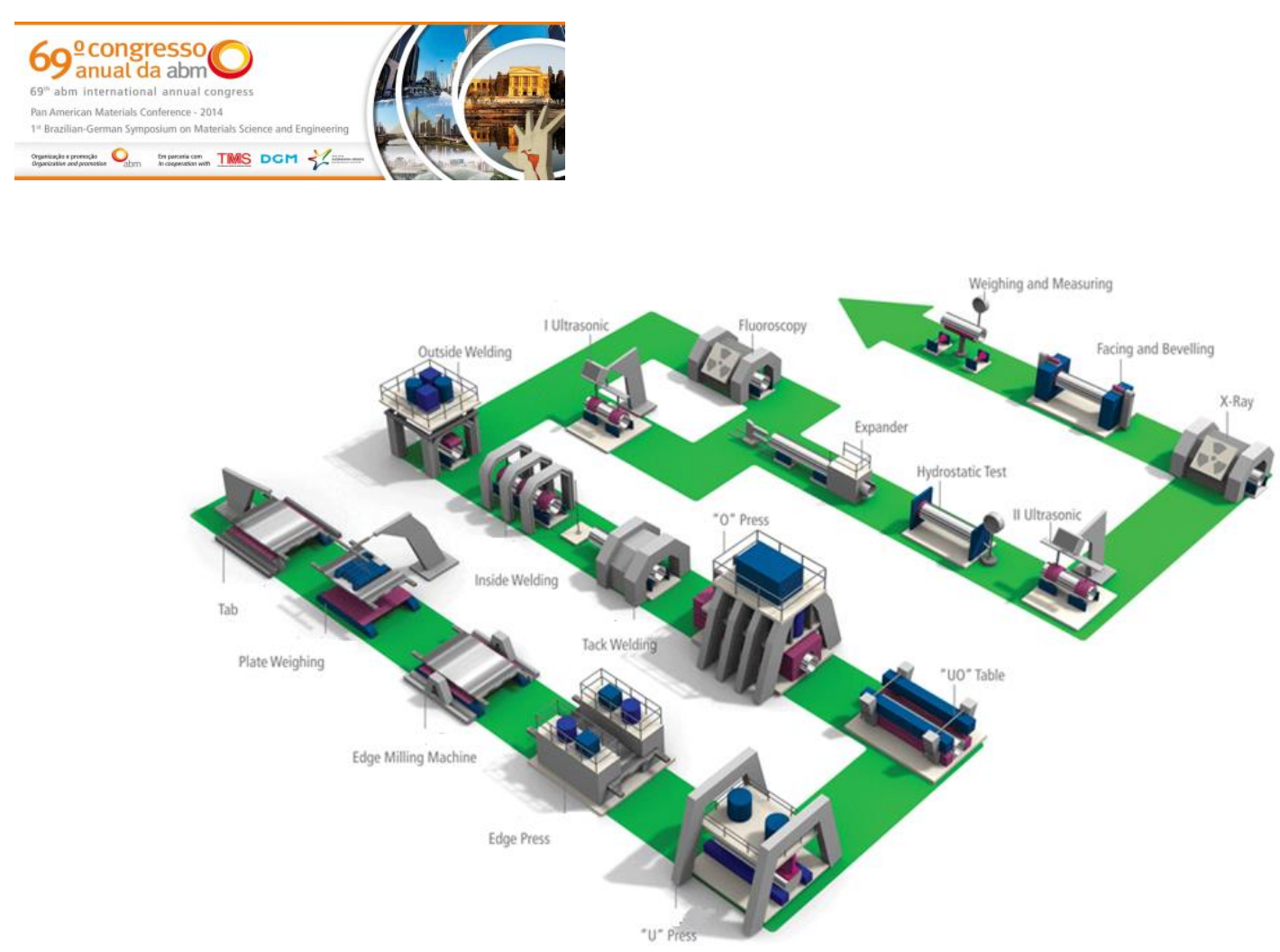

Figura 3. Diagrama de fabricação de tubos SAWL da Tenaris [5]

Durante o processo de conformação mecânica, a chapa e, consequentemente o tubo, sofrem deformações compressivas e trativas, conforme exemplificado na figura 4. Estas deformações, aliadas à microestrutura presente, causam uma variação das propriedades mecânicas. Para tubos de baixo t/D, Stalheim, Barnes e McCutcheon [6] concluíram que materiais com microestrutura com predominância de ferrita e perlita geralmente levam a uma redução do limite de escoamento de chapa para tubo, enquanto microestruturas com predominância de ferrita acicular, que neste trabalho é denominada de bainita, levam a um aumento do limite de escoamento. Já Rosado, De Waele, Vanderschueren e Hertelé [7] concluíram que a variação de propriedade mecânica entre chapa e tubo é dependente das frações volumétricas das fases e que materiais dual phase apresentam um aumento no limite de escoamento durante a formação do tubo maior que materiais de fase única.
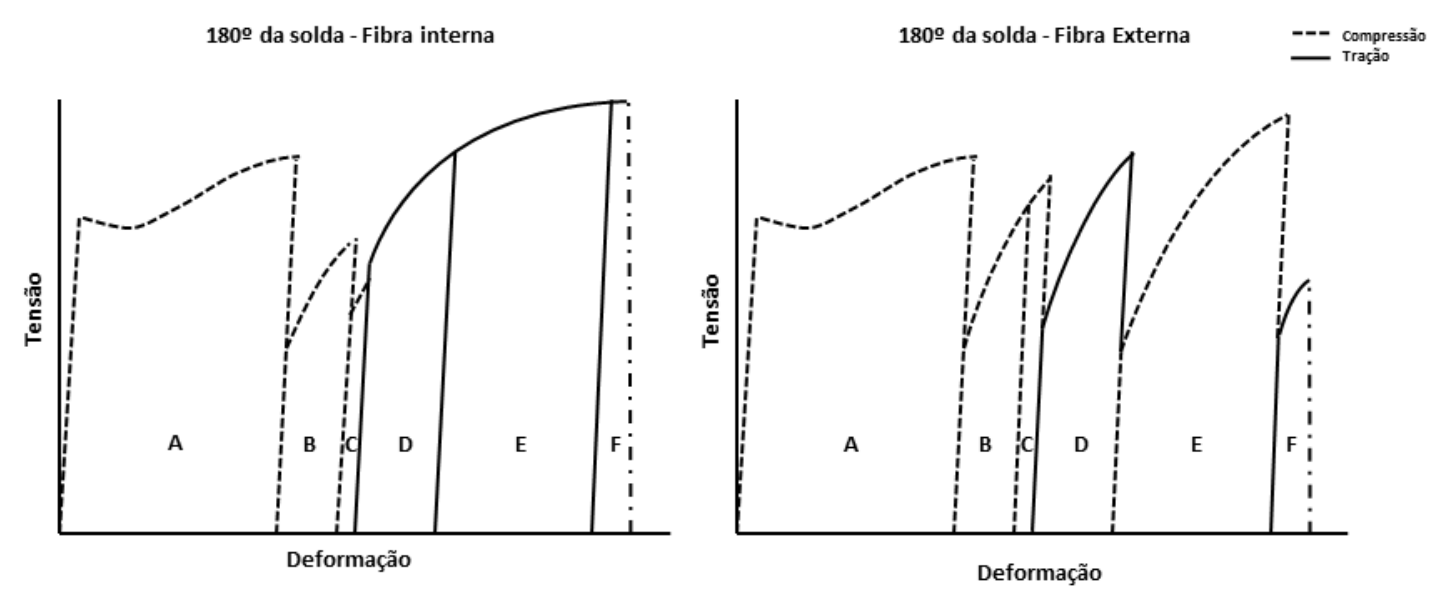

Figura 4. Tensões esquemáticas durante o processo UOE e ensaio de tração. a) Prensa "U", b) Formação na prensa "O", c) Compressão na prensa "O", d) Expansão, e) Endireitamento do corpo de prova, f) Ensaio de tração com offset de 0,5\% Fonte: Adaptado de [6].

* Contribuição técnica ao 69 Congresso Anual da ABM - Internacional e ao 14ํㅡㄹ ENEMET - Encontro Nacional de Estudantes de Engenharia Metalúrgica, de Materiais e de Minas, 21 a 25 de julho de 2014, São Paulo, SP, Brasil. 


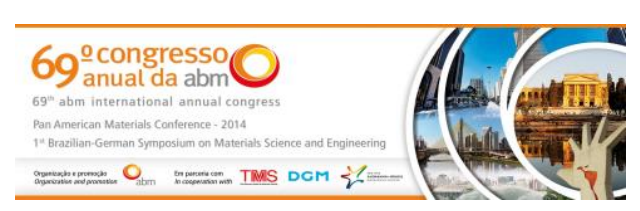

carbonetos em coloração mais escura. O microconstituinte MA aparece em coloração esbranquiçada, principalmente como segregado da fase bainítica.
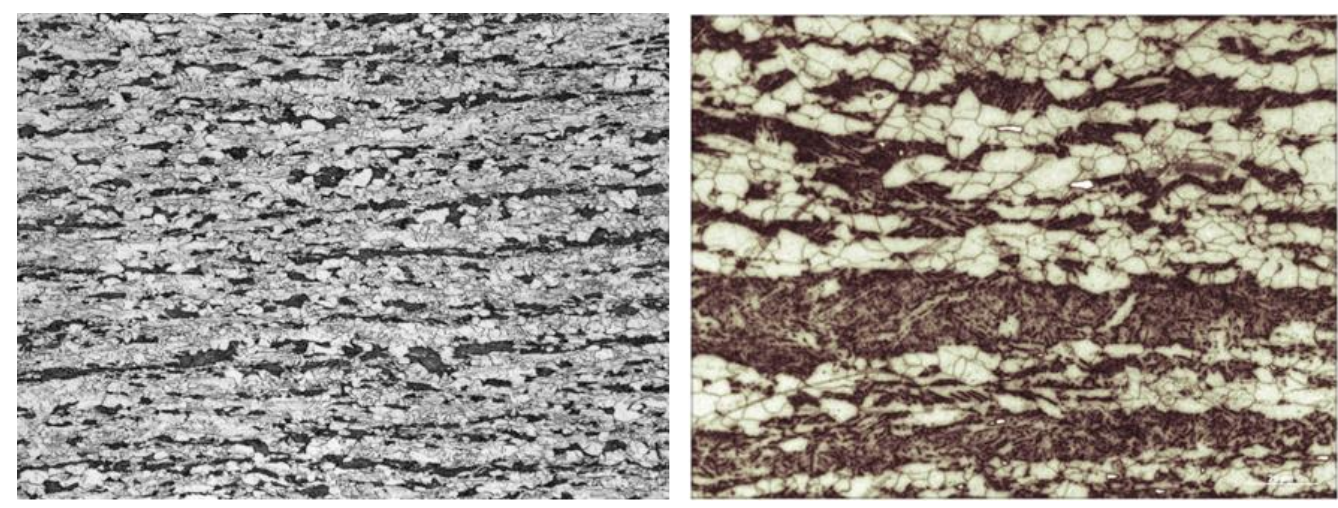

Figura 5. Amostra C atacada com: a) Nital 3\% - Aumento de 200x.b) LePera - 500x.

Os ensaios de tração foram realizados conforme ASTM A370 [10] e API 5L [11]. Foram considerados os pontos UYS (Limite de escoamento superior) e LYS (Limite de escoamento inferior), conforme ASTM E8 [12], e considerando-se o limite de escoamento de curvas que não apresentam descontinuidade como a tensão à $0,5 \%$ de deformação.

\section{RESULTADOS E DISCUSSÃO}

Através da caracterização e quantificação microestrutural, é possível observar as diferenças existentes para os distintos materiais em estudo. Observa-se que a morfologia básica produzida no aço microligado é de uma matriz ferrítica (clara) com ilhas de segunda fase (escura), composta por bainita irregular ou granular. No entanto, a morfologia e distribuição das fases também são alteradas de acordo com a amostra e, consequentemente, seu processo de formação, de modo que foram observados casos com bandeamento acentuado da fase bainita irregular. As figuras 6 e 7 mostram as microestruturas obtidas de cada material com o ataque Nital 3\%.

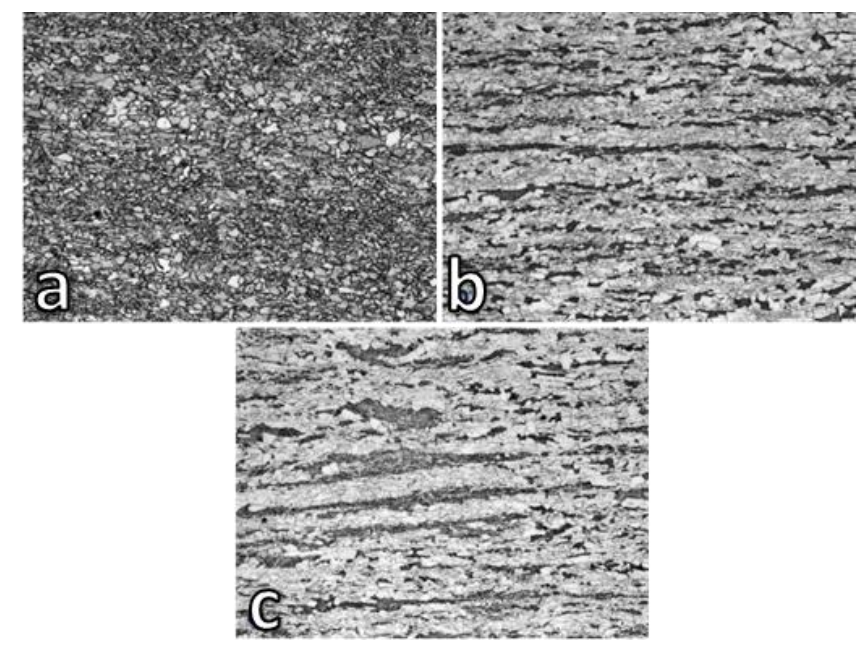

Figura 6. Microestruturas materiais X70. Nital 3\%. Aumentos de 200x. a) Material A - Presença de ilhas de ferrita poligonal numa matriz bainítica; b) Material B - É possível observar a distinção da fase ferrítica e austenita retida (regiões claras) com relação às demais, que se apresentam de maneira bandeada; c) Material C - É possível observar a distinção da fase ferrítica e austenita retida (regiões claras) com relação às demais, que se apresentam de maneira bandeada.

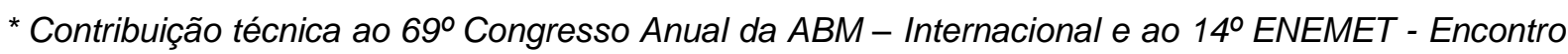
Nacional de Estudantes de Engenharia Metalúrgica, de Materiais e de Minas, 21 a 25 de julho de 2014, São Paulo, SP, Brasil.
} 

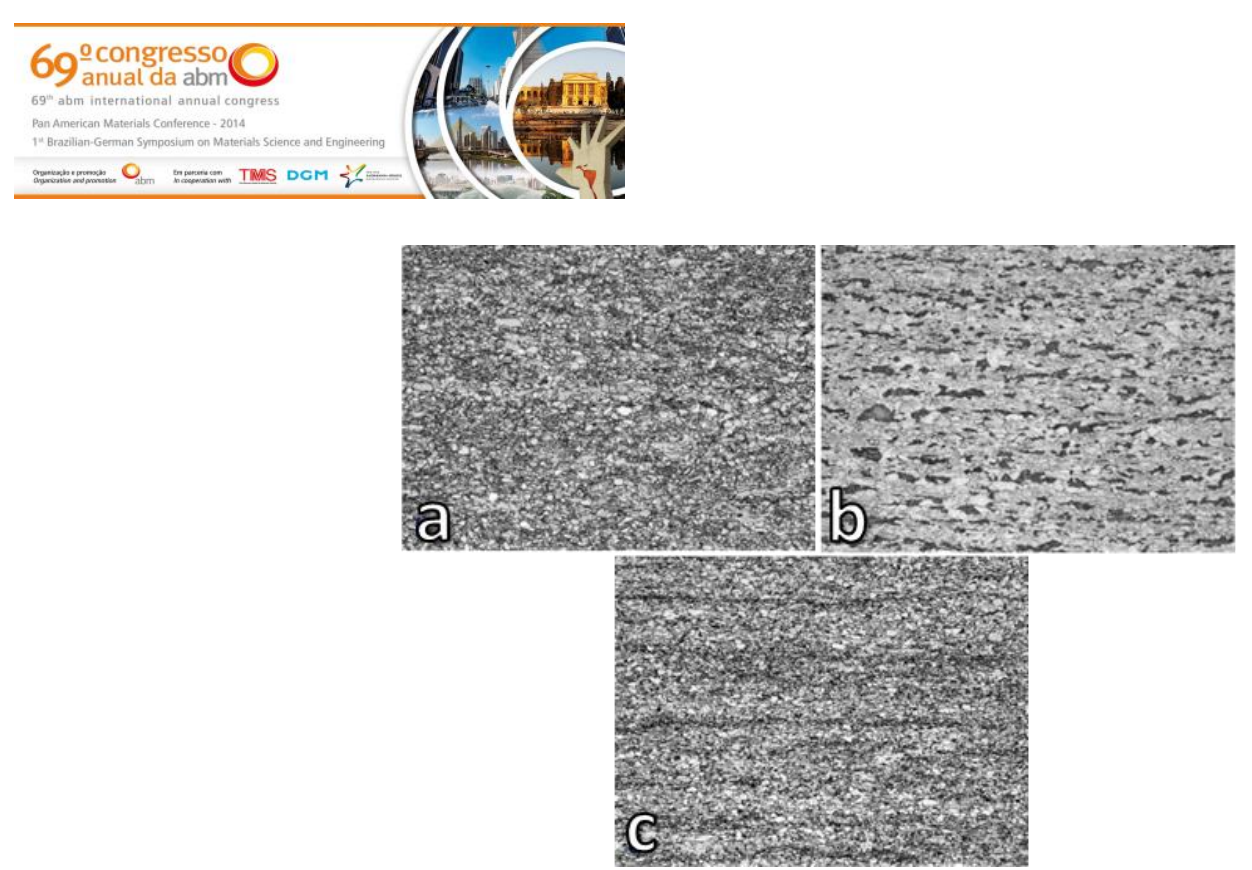

Figura 7. Materiais X80. Nital 3\%. Aumentos de 200x. Microestruturas a e c) Materiais D e F, respectivamente - É possível observar a presença de pequenas ilhas de ferrita poligonal numa matriz predominantemente bainítica; b) Material E - É possível observar a distinção da fase ferrítica e austenita retida (regiões claras) com relação às demais, que se apresentam de maneira bandeada.

Através da técnica de quantificação por tríplice ataque foi possível a formulação de um sistema de equações no qual foram analisadas as porcentagens obtidas e distinguido a fração volumétrica de cada fase.

Na figura 8, é possível observar as micrografias da amostra A após os diferentes ataques, e o método de quantificação utilizado, e a tabela 2 sintetiza as quantificações encontradas para todas as amostras de estudo. Como não foi verificada a presença de austenita retida na matriz das amostras, esta fase não foi contabilizada para a distinção das frações volumétricas.
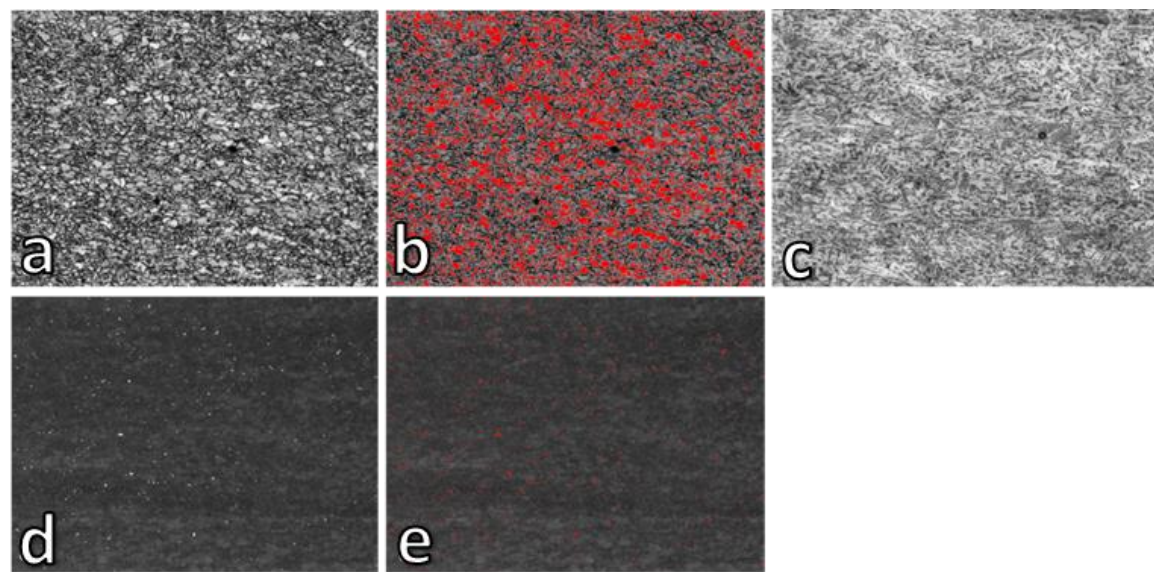

Figura 8: Micrografias do material A. Aumentos de 200x. a) Ataque Nital 3\%; b) Quantificação das fases ferrita e austenita retida, em vermelho; c) Ataque com metabissulfito de sódio; $10 \%$ d) Ataque LePera; e) Quantificação da fase MA, em vermelho.

Tabela 2. Resultado das Análises de quantificação de fases.

\begin{tabular}{cccc}
\hline Material & \% Ferrita & \% Bainita & \% MA \\
\hline A & $20,4 \pm 0,65$ & $78,7 \pm 0,65$ & $0,87 \pm 0,04$ \\
\hline B & $29,9 \pm 0,62$ & $70,0 \pm 0,62$ & $0,13 \pm 0,03$ \\
\hline C & $59,5 \pm 0,37$ & $40,3 \pm 0,38$ & $0,20 \pm 0,06$ \\
\hline D & $11,1 \pm 0,73$ & $88,6 \pm 0,73$ & $0,27 \pm 0,04$ \\
\hline E & $25,1 \pm 0,92$ & $74,8 \pm 0,92$ & $0,13 \pm 0,01$ \\
\hline F & $22,7 \pm 0,61$ & $77,2 \pm 0,61$ & $0,14 \pm 0,02$ \\
\hline \multicolumn{3}{c}{ Intervalos de confiança de $95 \%$}
\end{tabular}

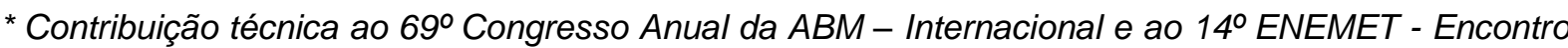
Nacional de Estudantes de Engenharia Metalúrgica, de Materiais e de Minas, 21 a 25 de julho de 2014, São Paulo, SP, Brasil.
} 


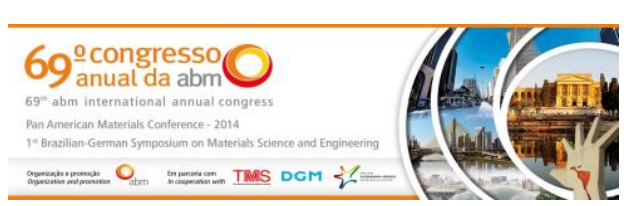

A técnica do tríplice ataque mostrou-se bastante eficaz na diferenciação e quantificação estatística da fração volumétrica das fases presentes na amostra. No entanto, algumas microestruturas, como por exemplo, os aços $\mathrm{D}$ e $\mathrm{F}$ atacados com o reagente Nital 3\%, apresentaram-se com uma morfologia bastante complexa e de difícil diferenciação entre as fases da matriz, o que pode dificultar a interpretação para a quantificação. Os resultados obtidos são, portanto, valores aproximados, porém representativos, da fração volumétrica real. Através das análises, foi possível observar um aumento na porcentagem de bainita para materiais X80 quando comparados a materiais $\mathrm{X} 70$, e sua distinta morfologia alterando de irregular para formatos granulares para diferentes fornecedores. Essas características microestruturais são provenientes de diferenças no processo de fabricação da chapa grossa, e afetam diretamente as propriedades mecânicas finais do material.

A figura 9 mostra o resultado do ensaio de tração de chapa e de tubo proveniente de diferentes fornecedores. À esquerda é possível observar que a chapa apresentava região de patamar de escoamento descontinuo, típico de chapas laminadas a quente com microestrutura mesclada de ferrita / bainita, enquanto à direita é possível observar a curva de chapas laminadas a quente com microestrutura bainítica.

Em ambos os casos, o tubo após conformado já não apresenta região de patamar de escoamento descontinuo e apresenta uma elevação do limite de escoamento, aliada a uma redução do alongamento final. Este comportamento é típico de material que sofreu encruamento devido ao trabalho mecânico a frio, e é desejável em produtos que devam suportar deformações elásticas e plásticas durante seu ciclo de formação. Este comportamento é importante para o produto final uma vez que a partir dele é possível calcular quais as tensões e deformações que o tubo será capaz de suportar durante a fase de instalação e o ciclo de vida da linha transportadora, como demonstrado por Willian Mohr [3].
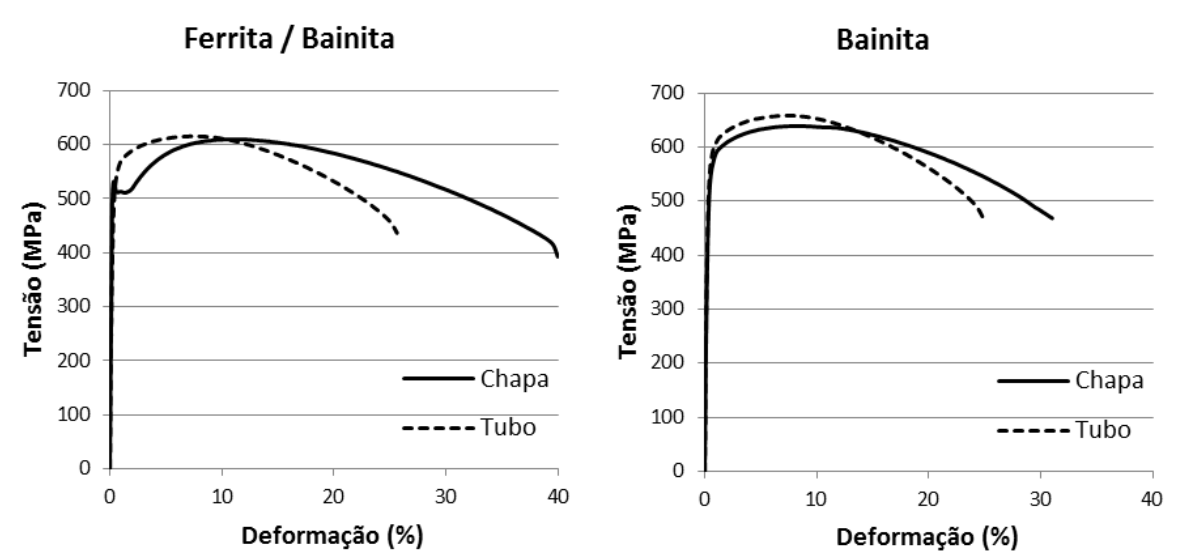

Figura 9. Curvas de tração transversal de chapa e tubo.

Através da quantificação de fases e das variações de propriedade mecânica de chapa para tubo das amostras, foi possível obter uma relação entre fração volumétrica de bainita e a variação de limite de escoamento médio de chapa para tubo, conforme mostra a figura 6.

\footnotetext{
* Contribuição técnica ao $69^{\circ}$ Congresso Anual da ABM - Internacional e ao 14ํㅡㄹ ENEMET - Encontro Nacional de Estudantes de Engenharia Metalúrgica, de Materiais e de Minas, 21 a 25 de julho de 2014, São Paulo, SP, Brasil.
} 

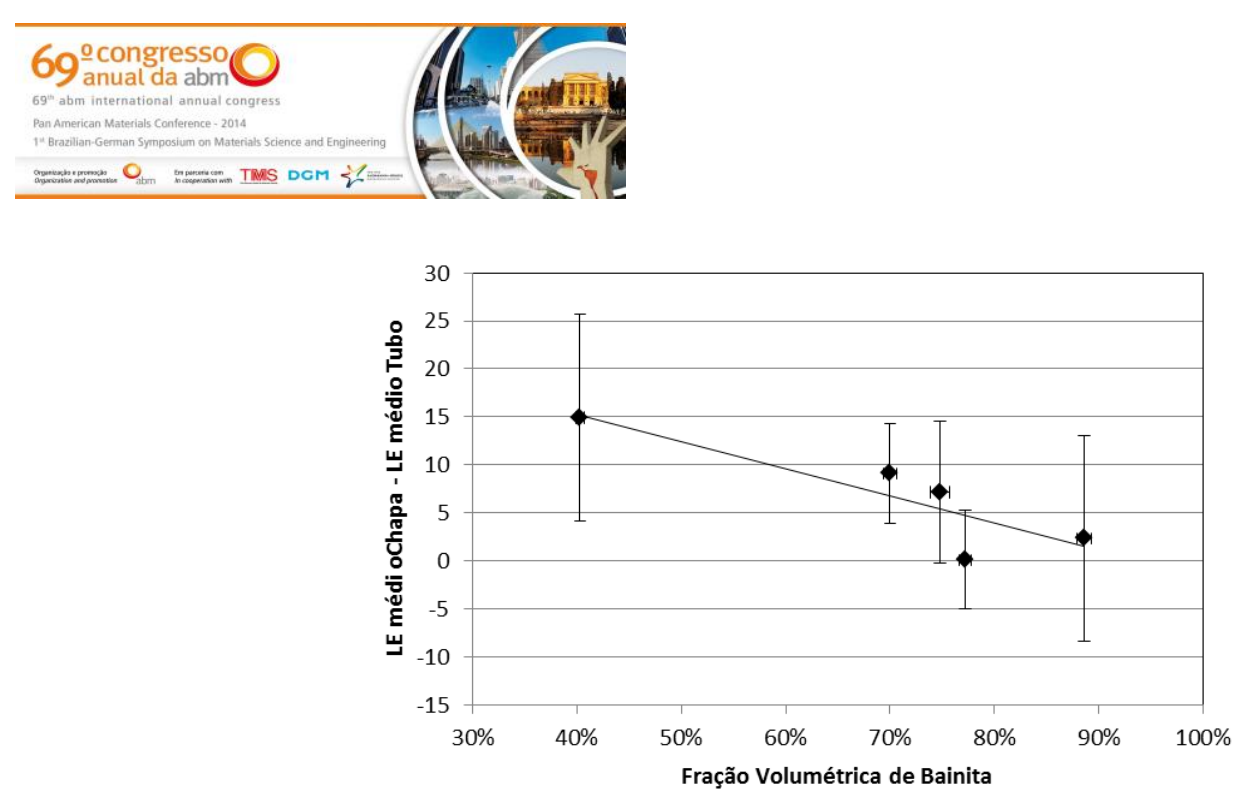

Figura 10. Relação entre fração volumétrica de bainita e delta limite de escoamento médio entre chapa e tubo para os diferentes materiais testados (Intervalos de confiança de 95\%).

A relação apresentada pela figura 10 demonstra que a variação de limite de escoamento médio de chapa para tubo é reduzida conforme a fração volumétrica de bainita aumenta. Este resultado é contraditório ao encontrado por Stalheim et al [6] porém esta de acordo com o resultado encontrado por Rosado et al [10]. Desta maneira é possível supor correta a afirmação que para menores frações volumétricas de bainita, prevalecendo assim a existência de um material dual phase, o limite de escoamento médio dos tubos deverá ser maior que o limite de escoamento médio das chapas. Este efeito está relacionado à presença da matriz ferritica, que apresenta menor resistência e maior ductilidade do que a matriz bainitica. Desta maneira, o efeito do encruamento nestes aços, principalmente na região do calculo do limite de escoamento, é mais intenso.

A mesma relação pode ser observada na figura 11, onde são apresentadas as relações dentre limites de escoamento em chapa e em tubo para corridas individuais para diferentes fornecedores. Nesta figura os fornecedores foram divididos entre a microestrutura predominante.

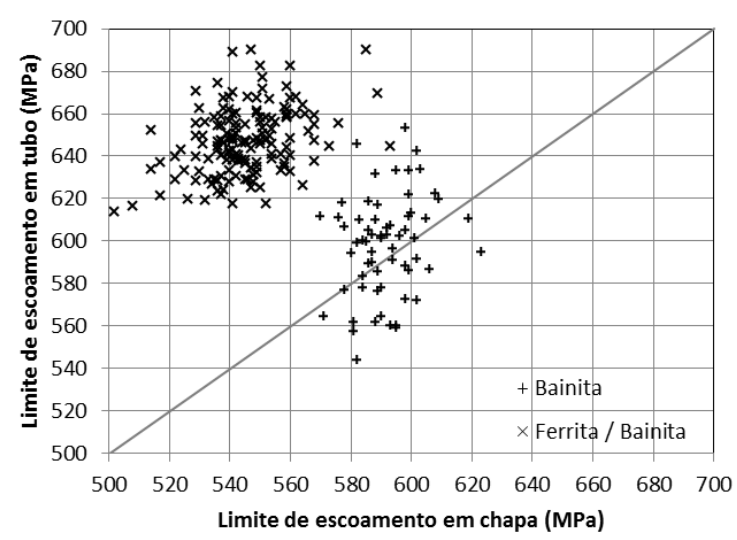

Figura 11. Relação entre principal fase presente e variação de limite de escoamento de chapa para tubo.

\section{CONCLUSÃo}

Através da relação microestrutural com as propriedades mecânicas dos produtos, pode-se concluir que, conforme maior a porcentagem da fase bainítica presente na matriz do aço, menor será a variação de propriedades mecânicas durante a conformação da chapa grossa em tubo. Esse resultado pode ser confirmado através

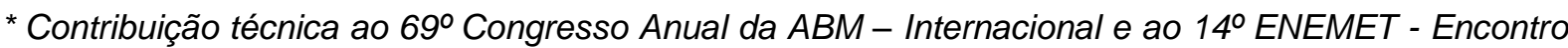
Nacional de Estudantes de Engenharia Metalúrgica, de Materiais e de Minas, 21 a 25 de julho de 2014, São Paulo, SP, Brasil.
} 


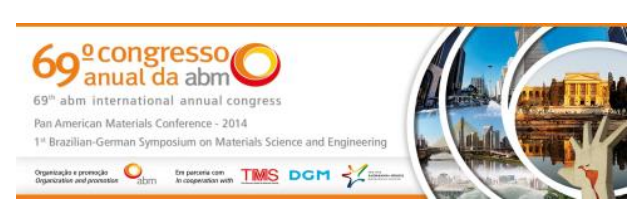

das curvas de tensão $\mathrm{x}$ deformação obtidas para materiais ferríticos/bainíticos e materiais bainíticos, de modo que este último não apresenta UYS e LYS em chapa e sofre pouca variação de limite de escoamento quando conformado em tubo. Este resultado está de acordo com os resultados encontrados por Rosado et al [7] e em desacordo com os resultados encontrados por Stalheim et al [6]. O motivo do desacordo pode ser relacionado ao diferente t/D dos materiais observados, assim como os diferentes processos de fabricação de tubos apresentados por Stalheim.

Os resultados deste artigo permitem um conhecimento prévio do comportamento mecânico do material durante seus ciclos de deformação de fabricação e devem ser utilizado nos cálculos de resistência a falha quando existe deformação nas linhas transportadoras de óleo e gás, como demostrado por Mohr [3].

Os resultados obtidos são também de extrema importância para o conhecimento industrial uma vez que a ciência do comportamento mecânico permite uma maior acuidade no desenvolvimento de novos produtos para ambientes cada vez mais críticos, conforme a demanda do mercado.

\section{Agradecimentos}

Agradecemos à Tenaris do Brasil pelos dados, laboratórios e materiais fornecidos para a confecção deste artigo

\section{REFERÊNCIAS}

$1 \quad$ BP Statistical Review of World Energy June 2013

2 Sanderson N, Ohm R, Jacobs M. Study of X-100 line pipe costs points to potential savings. Oil \& Gas Journal, 1999; 97(11).

3 Mohr W. Report on Strain-Based Design of pipelines to U.S. Department of Interior, Minerals Management Service and U. S. Department of Transportation, Research and Special Programs Administration. 2003.

4 Nafisi S, Arafin MA, Collins L, Szpunar J. Texture and mechanical properties of API X100 steel manufactured under various thermomechanical cycles. Materials and Science Engineering, 2012; 531(1): 2-11.

5 Moreira FA, Chad LC, Leon HR, Souza MP. Tubo de aço carbono com alta resistência a corrosão para transporte offshorede óleo e gás com presença de CO2 e H2S, Conferência Tecnologia de Equipamentos COTEQ - 2009.

6 Stalheim DG, Barnes KR, McCutcheon DB. Alloy designs for high strength oil and gas transmission linepipe steels. Procedings of the International Sysmposium on Microalloyed Steels for the Oil and Gas Industry, 2006, pg.73-108.

7 Rosado B, Waele W, Vanderschueren D, Hertelé S. Lateste Developments in mechanical properties and metallurgical features of high strength line pipe steels. Sustainable Construction and Design. 2013

8 Colpaert H. Metalografia dos produtos siderúrgicos comuns, Edgard Blücher, 1983.

9 Anazawa RM, Abdalla AJ, Pereira,MS, Hashimoto TM, Carrer GR. Anais do

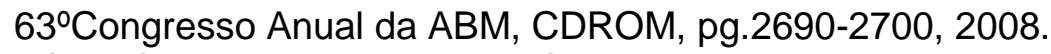

10 ASTM Standard A370 2012a, "Standard Test Methods and Definitions for Mechanical Testing of Steel Products," ASTM International, West Conshohocken, PA, 2012, DOI: 10.1520/A0370-12a, www.astm.org.

11 American Petroleum Insititute Standard API 5L 45 "th "Specification for Line Pipe", American Petroleum Insititute, 2012.

12 ASTM International. ASTM Standard E8/E8M 2013르: Standard Test Methods for Tension Testing of Metallic Materials. West Conshohocken; 2013, DOI: 10.1520/E0008_E0008M-13A, www.astm.org.

\footnotetext{
* Contribuição técnica ao $69^{\circ}$ Congresso Anual da ABM - Internacional e ao 14ํㅡㄹ ENEMET - Encontro Nacional de Estudantes de Engenharia Metalúrgica, de Materiais e de Minas, 21 a 25 de julho de 2014, São Paulo, SP, Brasil.
} 